\title{
Fracture of metals samples under conditions of fast heating by intensive X-ray radiation
}

\author{
V.K. Golubev \\ Russian Federal Nuclear Center - VNIIEF, Sarov, Russia
}

\begin{abstract}
Results on studying the fracture of metals samples in the form of thin disks under fast heating by the X-ray pulse with the complete spectrum are presented in the paper. The samples of such metals as iron, copper, AMg6 aluminum, VT14 titanium, molybdenum, tungsten, cadmium, lead and zinc were tested. The samples were fixed in the special cartridges equipped with the gauges of a mechanical recoil momentum. The cartridges with samples were placed at such distances from the X-ray irradiator where the energy fluxes were $1.38,0.90$ and $0.29 \mathrm{~kJ} / \mathrm{cm}^{2}$. The irradiating X-ray pulse was about $2 \mathrm{~ns}$ in duration. After testing, the depth of material ablation from a sample front surface and the degree and character of its spall damage were determined. The method of metallographic analysis was used for these purposes. Numerical calculations of loading conditions were made with the use of an equation of state taking into account the process of evaporation. The calculated value of maximum negative pressure in the sample at the coordinate corresponding to the formation of spallation zones or spall cracks was conventionally accepted as the material resistance to spall fracture. The comparison of obtained results with the data on the fracture of examined materials in the conditions of fast heating by the X-ray pulse with the hard spectrum and a high-current electron beam was conducted.
\end{abstract}

\section{Introduction}

Fracture of metals samples in the form of thin disks under fast heating by intensive X-ray radiation was studied in a number of research works. Mention may be made of some of the works of the group of VNIIEF researchers, who engaged in this problem most thoroughly and published a lot of results for the considerable number of metals and alloys [1-5]. In these works metal samples from 0.005 to $1 \mathrm{~mm}$ in thickness were irradiated by the short-time X-ray pulse with the spectrum in which a soft part was filtered. In such a case the possibility of evaporation and fusion of materials on the front surfaces of tested samples was excluded from consideration that gave the chance of studying the spallation phenomenon in rather clear experimental conditions. After irradiation of a series of samples, the facts of presence or absence of developed spall fracture were established in each of them. The profile of energy released in a sample was determined by calculation and the energy value average through the thickness of a sample was used for subsequent determination of the maximum tensile stress and characteristic time of its action. Thus the dependences of critical tensile stresses resulted in spall fracture on characteristic loading time were constructed in a wide range of time, approximately from $10^{-9}$ to $10^{-6} \mathrm{~s}$. For the first time such results were published for copper [1]. The subsequent results were presented for nickel, titanium, bronze and brass, and the results for copper were appreciably supplemented [2]. Then the results for molybdenum, tantalum, tungsten, cadmium, lead, zinc and silver [3], for five steels $(08,10,65 \mathrm{G}, 60 \mathrm{~S} 2 \mathrm{~A}, \mathrm{Kh} 18 \mathrm{~N} 10 \mathrm{~T})$ and for four alloys on the basis of nickel (36NKhTYu, $42 \mathrm{NKhTYu}, 50 \mathrm{NKhS}, 80 \mathrm{NKhS}$ ) [4] were presented too. Ultimate generalization of all the results obtained by this group was made in work [5] where the time dependences of critical tensile stresses were given for all examined metals and alloys and some analysis of revealed tendencies was made.
At the same time the other group of VNIIEF researchers studied fracture of metals samples under fast heating by a high-current electron beam. Mention may be made of some of the works of this group in which rather numerous results were published for a number of metals [6-8]. For the first time such results were published for tin, lead and cadmium [6]. Then these data were added by the results for copper, nickel, iron, titanium, tantalum and tungsten [7]. The results of executed calculations and experiments showed that spall fracture took place in the middle plane of a sample or in its neighbourhood even in the case of some deviations from the uniformity of a heating profile. It was also shown that in a range of heating time up to $20 \mathrm{~ns}$ the calculated amplitude and duration of tensile stress in the middle plane of a sample did not depend practically on heating time. Ultimate generalisation of all the results obtained by this group was made in work [8], where the time dependences of critical tensile stresses were given for all examined metals and all the used research methods were described in detail. It also should be noted that studying fracture of metal samples under fast heating by a high-current electron beam was conducted earlier and the results were presented in the works of various authors. For example, the works on studying spall fracture of 6061-T6 aluminum alloy, copper and titanium [9, 12], tantalum [10] and aluminum [11] can be mentioned. In works $[9,10]$ the results were obtained not only on the conditions of complete spall fracture of samples but also the on conditions of microdamage nucleation in them.

Some aspects of spall fracture of the samples of several metals under fast heating by the X-ray pulse with the complete spectrum are considered in the presented short review paper. In this case the character of loading and response of a sample becomes appreciably complicated as its surface layers directed to a radiation source absorb the radiation flux of a soft part of the spectrum. As a result of such absorption they undergo evaporation, fusion and ablation imparting a recoil pulse to the sample. It 


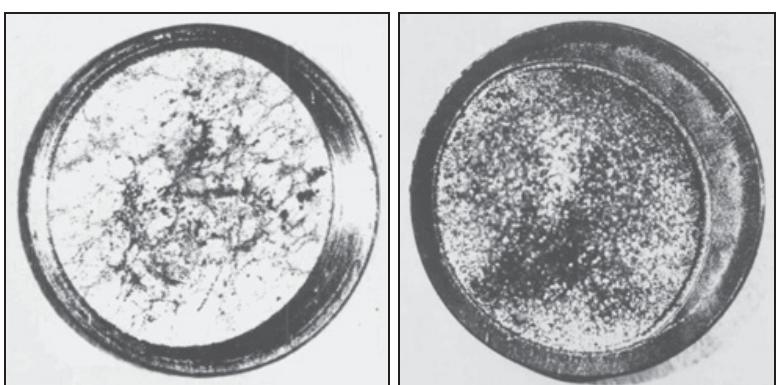

Fig. 1. The iron samples after irradiation by energy fluxes of $0.29 \mathrm{~kJ} / \mathrm{cm}^{2}$ (left) and $1.38 \mathrm{~kJ} / \mathrm{cm}^{2}$ (right).

is natural that studying the fracture process of samples under such loading conditions becomes more difficult in comparison with the two above mentioned cases of fast heating. However, the results obtained under these complicated loading conditions have an independent interest for reasoning and understanding the resistance of materials and structures to destruction in the situations of the real $\mathrm{X}$-ray radiation impact of high intensity. The part of results obtained in this direction was published and presented at several conferences before [13-21]. The data are extremely scattered and some aspects of fracture conditions were not presented there in full measure.

\section{Materials and procedures}

In the paper results obtained for iron, copper, $\mathrm{AMg} 6$ aluminum alloy, VT14 titanium alloy, tungsten, molybdenum, cadmium, lead and zinc are presented. The thicknesses of metal samples were chosen on the assumption of their surface density about $0.5 \mathrm{~g} / \mathrm{sm}^{2}$ and were oriented to the conditions of complete destruction and ablation of materials at the position nearest to the irradiation source. The samples of E10 iron had a thickness of $0.68 \mathrm{~mm}$. The samples of AMg6 aluminum alloy $1.85 \mathrm{~mm}$ thick were produced of a rod-shaped material. The alloy had the structure of a homogeneous solid solution with the grains elongated in the direction of rolling. The samples of M1copper $0.56 \mathrm{~mm}$ thick were produced of a sheet material. The samples of VT14 titanium alloy had a thickness of $1.1 \mathrm{~mm}$. The samples of tungsten $0.25 \mathrm{~mm}$ thick and molybdenum $0.5 \mathrm{~mm}$ thick were produced of sheet materials. Their initial structure was characteristic for metals obtained by the method of powder metallurgy with a subsequent rolling. The samples of cadmium were made of two layers of foil, each $0.30 \mathrm{~mm}$ thick. The samples of zinc had a thickness of $0.71 \mathrm{~mm}$ and the samples of lead were $0.45 \mathrm{~mm}$ thick. The examined samples had diameters of 14 and $19 \mathrm{~mm}$.

The samples were placed in special cartridges equipped with the gauges of a mechanical recoil momentum and were closed by the spacets of polyfoam with a density of $0.6 \mathrm{~g} / \mathrm{sm}^{3}$ at the rear and of $0.05 \mathrm{~g} / \mathrm{sm}^{3}$ at the front. Two identical samples were tested in each irradiation position. The intensity of irradiation of the samples was varied by their distances from the X-ray radiation source. The samples of all metals were tested on the impact of X-rays pulses with energy fluxes $J_{0}=1.38,0.90$ and $0.29 \mathrm{~kJ} / \mathrm{sm}^{2}$.

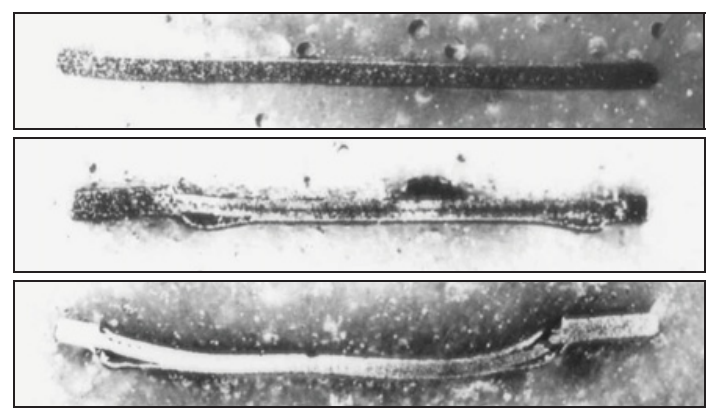

Fig. 2. The sections of iron samples after irradiation by energy fluxes of $0.29,0.90$ and $1.38 \mathrm{~kJ} / \mathrm{cm}^{2}$ (from top to bottom).
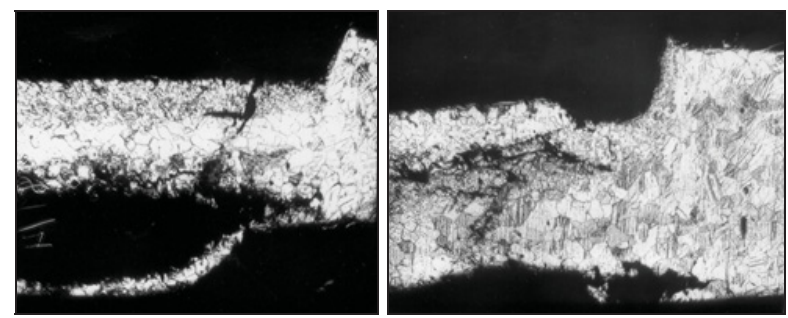

Fig. 3. Fragments of iron samples sections after irradiation by energy fluxes of $0.90 \mathrm{~kJ} / \mathrm{cm}^{2}$ (left) and $1.38 \mathrm{~kJ} / \mathrm{cm}^{2}$ (right).

Some samples were also tested at $J_{0}=0.42 \mathrm{~kJ} / \mathrm{sm}^{2}$. The duration of radiation pulse was about $2 \mathrm{~ns}$. The method of metallographic analysis of longitudinal sections was used as a main method for examining damage of the samples recovered after testing. Some other methods were also used for studying the properties of irradiated and damaged materials. Measuring the depth of material ablation from the front surface and examination of the degree and character of spall fracture was carried out for all tested samples.

The calculations of thermal energy extracted during the exposure of samples to X-rays radiation were carried out using an engineering procedure calibrated with Monte-Carlo calculation results. Numerical calculations of thermomechanical loading conditions of the samples were conducted with the use of the equation of state taking into account evaporation, fracturing and compacting of materials [22]. Fitting of parameters of this equation of state for all examined metals was fulfilled in work [19]. The calculations were carried out using a one-dimensional gas-dynamic program included into the computation complex [23].

\section{Obtained results}

Some results on fracture of iron samples [14] are presented in Figs. 1-4. In the figures, $b$ is the breadth of a zone. Irradiation of samples by energy fluxes of 1.38, 0.90 and $0.29 \mathrm{~kJ} / \mathrm{cm}^{2}$ resulted in material ablation up to depths of $0.08,0.055$ and $0.015 \mathrm{~mm}$ and recrystallization (grain refinement) up to depths of $0.24,0.15$ and $0.05 \mathrm{~mm}$. In the sample situated at the first level of irradiation, the zones of intensive spallation were placed at distances of about 0.12 and $0.44 \mathrm{~mm}$ from the rear surface. In the sample situated at the second level, the zones of intensive spallation were placed at distances of about 0.13 and $0.34 \mathrm{~mm}$ from the 


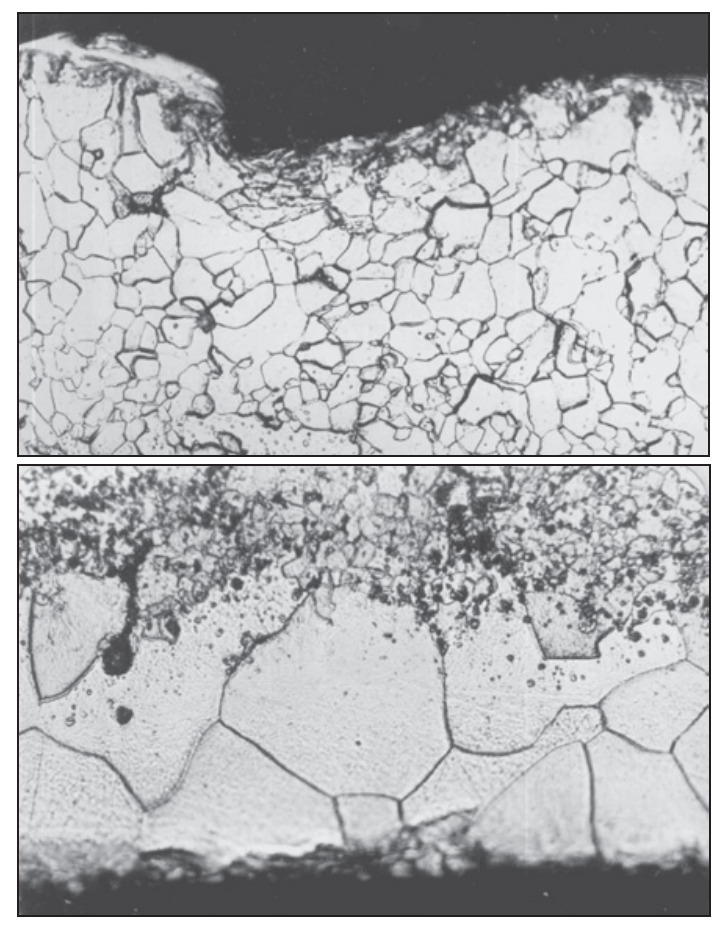

Fig. 4. The structures of an iron sample after irradiation by an energy flux of $0.90 \mathrm{~kJ} / \mathrm{cm}^{2}$ near the front (top) and rear (bottom) surfaces $(b=198 \mu \mathrm{m})$.

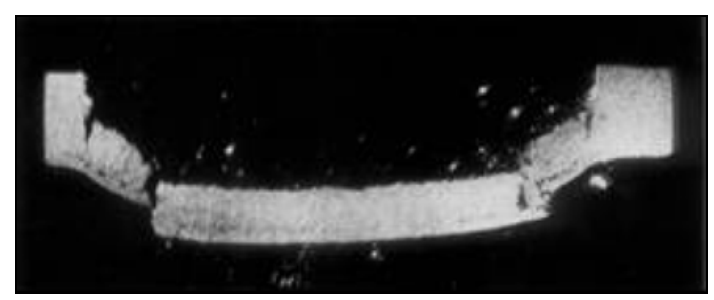

Fig. 5. The section of an AMg6 alloy sample after irradiation by an energy flux of $0.90 \mathrm{~kJ} / \mathrm{cm}^{2}$.

rear surface. The formed spall microdamages looked like small pores situated with a high density in spallation zones. In the sample situated at the third level, no spall damages were observed.

Some results on fracture of AMg6 aluminum alloy samples [15] are presented in Figs. 5, 6. Irradiation of samples by energy fluxes of $1.38,0.90$ and $0.29 \mathrm{~kJ} / \mathrm{cm}^{2}$ resulted in material ablation through a complete thickness, up to depths of 0.75 and $0.20 \mathrm{~mm}$. In the sample situated at the second level, the zone of intensive spallation was placed at a distance of about $0.25 \mathrm{~mm}(0.18-0.33 \mathrm{~mm})$ from a rear surface and the zone of partial damage was placed at a distance up to $0.62 \mathrm{~mm}$. Intergranular cracks were observed in the front surface layer of the sample. The surface itself was rough with traces of tearing the metal. In the sample situated at the third level of irradiation, no spall damages were observed. The character of damage of the front surface layer was similar to that in the sample at the second level of irradiation.

Some results on fracture of copper samples $[16,18]$ are presented in Fig. 7. Irradiation of samples by energy fluxes of $1.38,0.90$ and $0.29 \mathrm{~kJ} / \mathrm{cm}^{2}$ resulted in complete
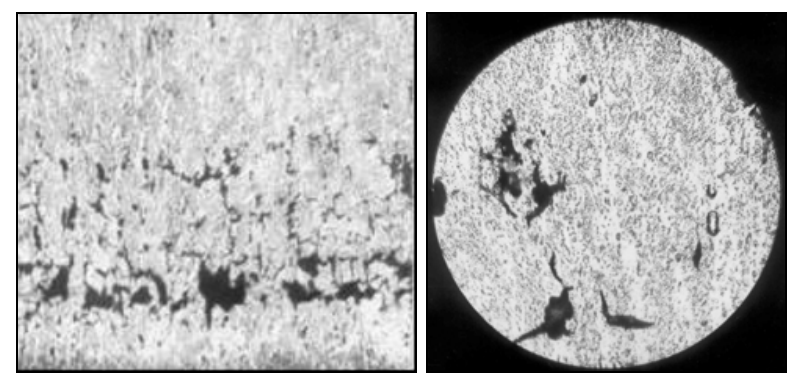

Fig. 6. The structure of an AMg6 alloy sample after irradiation by an energy flux of $0.90 \mathrm{~kJ} / \mathrm{cm}^{2}$ in the spall area $(b=1020 \mu \mathrm{m}$, left) and observed microdamages ( $b=172 \mu \mathrm{m}$, right).

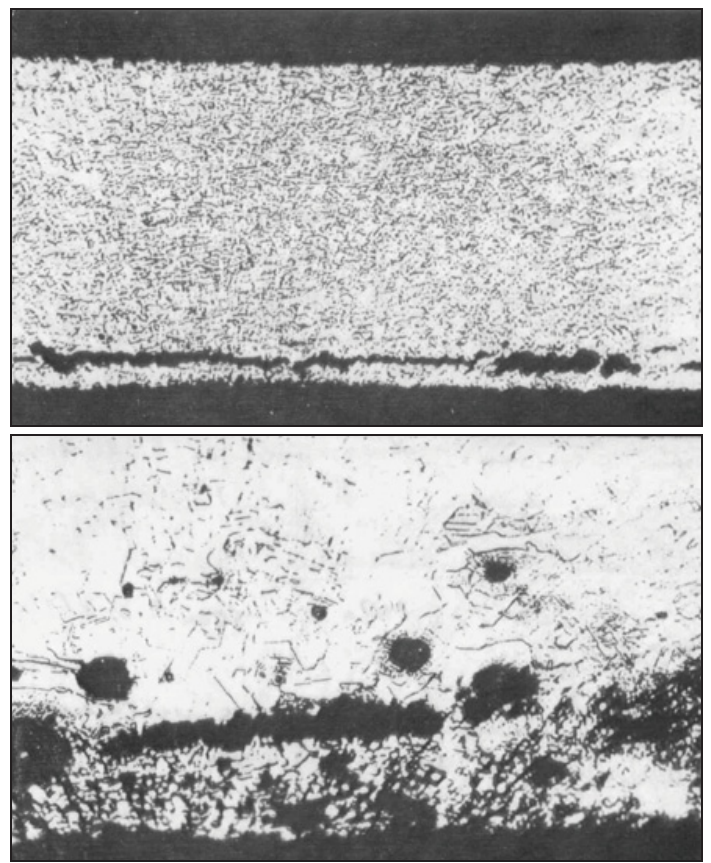

Fig. 7. A fragment of a copper sample after irradiation by an energy flux of $0.29 \mathrm{~kJ} / \mathrm{cm}^{2}$ (top) and the scaled-up fragment of the spall area (bottom).

material ablation, considerable destruction and dispersion, and material ablation up to a depth of about $0.11 \mathrm{~mm}$. The spall crack was situated at a distance of about $0.03 \mathrm{~mm}$ from the rear surface.

Some results on fracture of VT14 titanium alloy are presented in Fig. 8. In the sample situated at the first level of irradiation, considerable ablation and spallation were observed. The first spall layer had a thickness of about $0.12 \mathrm{~mm}$ and microdamages were observed starting from a distance of $0.10 \mathrm{~mm}$ from the rear surface. The intensity of such damage was a little smaller at the second level. The first spall layer had a thickness of about $0.13 \mathrm{~mm}$ and microdamages were observed starting from a distance of $0.12 \mathrm{~mm}$ from the rear surface. In the sample situated at the third level, slight ablation and no spall damages were observed.

Some results on fracture of tungsten $[13,21]$ are presented in Fig. 9. Irradiation of samples by energy fluxes of $1.38,0.90$ and $0.29 \mathrm{~kJ} / \mathrm{cm}^{2}$ resulted in material ablation up to depths of $0.13,0.05$ and $0.01 \mathrm{~mm}$. The samples situated at the first and second levels of irradiation 


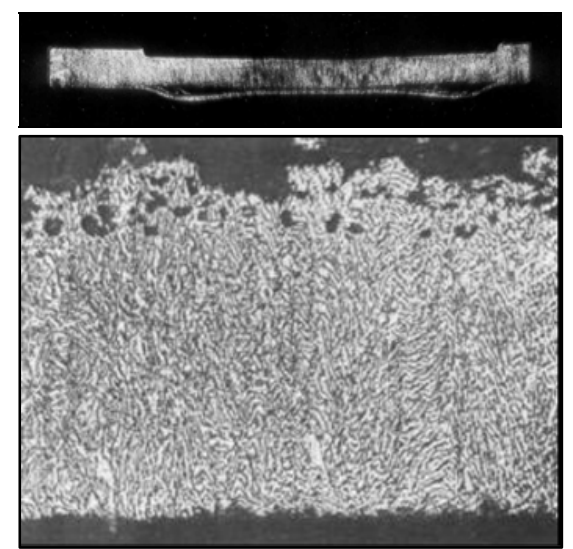

Fig. 8. The section of a VT14 alloy sample after irradiation by an energy flux of $0.90 \mathrm{~kJ} / \mathrm{cm}^{2}$ (top) and the structure of its spall layer (bottom, $b=202 \mu \mathrm{m}$ ).

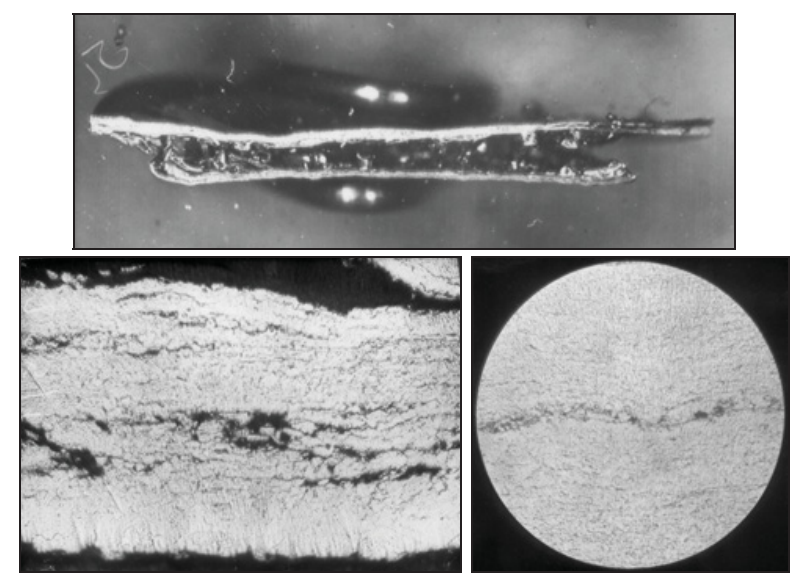

Fig. 9. The section of a tungsten sample after irradiation by an energy flux of $0.90 \mathrm{~kJ} / \mathrm{cm}^{2}$ (top), the structure of its spall layer (left, $b=223 \mu \mathrm{m}$ ) and a microdamage in the structure of a sample after irradiation by an energy flux of $0.29 \mathrm{~kJ} / \mathrm{cm}^{2}$ (right, $b=168 \mu \mathrm{m})$.

underwent substantial spall fracture. Only separate damages in the form of microcracks elongated in the direction of technological rolling were observed in the sample irradiated by a minimal flux.

Some results on fracture of molybdenum [13,21] are presented in Fig. 10. Irradiation of samples by energy fluxes of $1.38,0.90$ and $0.29 \mathrm{~kJ} / \mathrm{cm}^{2}$ resulted in material ablation up to depths about $0.15,0.10$ and $0.01 \mathrm{~mm}$. The samples situated at the first and second levels of irradiation underwent substantial spall fracture. Spall fracture was also observed in the sample irradiated by an energy flux of $0.42 \mathrm{~kJ} / \mathrm{cm}^{2}$. Separate microcracks elongated in the direction of technological rolling were observed in the sample irradiated by a minimal flux.

Samples of zinc, lead and cadmium [17,21] were irradiated by energy fluxes of $1.38,0.90$ and $0.29 \mathrm{~kJ} / \mathrm{cm}^{2}$. The zinc samples situated at the first two levels of irradiation underwent complete material ablation. At the third level the thickness of an ablation layer was $0.03 \mathrm{~mm}$ and no spall damages were observed in the sample. The complete material ablation of lead samples was noted at all

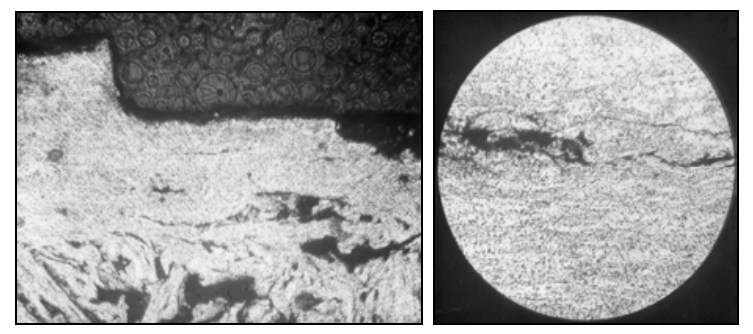

Fig. 10. A fragment of a molybdenum sample section after irradiation by an energy flux of $0.42 \mathrm{~kJ} / \mathrm{cm}^{2}$ (left) and a microdamage in the structure of a sample after irradiation by an energy flux of $0.29 \mathrm{~kJ} / \mathrm{cm}^{2}$ (right, $b=168 \mu \mathrm{m}$ ).

Table 1. Microhardness of samples before and after irradiation.

\begin{tabular}{|l|c|c|c|}
\hline Material & \multicolumn{2}{|c|}{$H_{\mu}, \mathrm{GPa}$ for } & \\
& $J_{0}=0 \mathrm{~kJ} / \mathrm{cm}^{2}$ and $0.29 \mathrm{~kJ} / \mathrm{cm}^{2}$ & $F, \mathrm{~N}$ \\
\hline Iron & $1.37 \pm 0.09$ & $0.98 \pm 0.04$ & 0.50 \\
\hline AMg6 alloy & $0.98 \pm 0.04$ & $2.16 \pm 0.11$ & 0.20 \\
\hline VT14 alloy & $3.33 \pm 0.20$ & $3.06 \pm 0.18$ & 1.00 \\
\hline Copper & $0.68 \pm 0.04$ & $0.80 \pm 0.02$ & 0.20 \\
\hline Tungsten & $4.72 \pm 0.31$ & $5.15 \pm 0.16$ & 1.00 \\
\hline Molybdenum & $3.67 \pm 0.15$ & $3.22 \pm 0.15$ & 0.50 \\
\hline Cadmium & $0.20 \pm 0.01$ & $0.26 \pm 0.03$ & 0.05 \\
\hline
\end{tabular}

three levels of irradiation. The cadmium sample situated at the first level of irradiation underwent complete material ablation. The complete ablation of the upper layer and considerable destruction of the lower layer were observed at the second level. At the third level the ablation of material of the upper layer was up to a depth of $0.10 \mathrm{~mm}$ and a significant spall fracture took place in both the layers.

Selective measurements of microhardness $H_{\mu}$ for some of the tested samples were carried out too. They were made on longitudinal sections in the places were the microdamge of materials was as little as possible. The results obtained, the average values of microhardness and root-mean-square deviations, are presented in Table 1 in comparison with the initial values obtained using the reference samples. An applied load $F$ was different for various materials.

The measurements of microhardness of were also fulfilled for the iron samples irradiated by fluxes of 0.90 and $1.38 \mathrm{~kJ} / \mathrm{sm}^{2}$. The values of $1.62 \pm 0.04$ and $1.57 \pm 0.08 \mathrm{GPa}$ were obtained for $H_{\mu}$ in these cases.

Some results of numerical calculations of loading conditions of some tested samples are presented in Fig. 11-16 for iron, AMg6 aluminum alloy, copper and molybdenum. It would be recalled that evaporation processes were taken into account but the subsequent calculations were conducted in hydrodynamic approach, that is without taking account of the shear strength of materials.

It can be partly justified because of high heating of the samples, but all the same the obtained values of maximal negative pressures on coordinates corresponding 


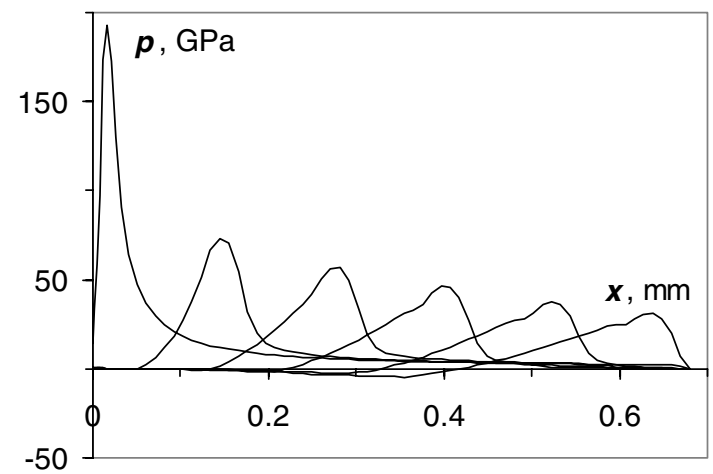

Fig. 11. The evolution of a compressive pulse in an iron sample under irradiation by an energy flux of $0.90 \mathrm{~kJ} / \mathrm{cm}^{2}: t=2.0,19.8$, $39.3,59.2,79.7$ and $99.7 \mathrm{~ns}$.

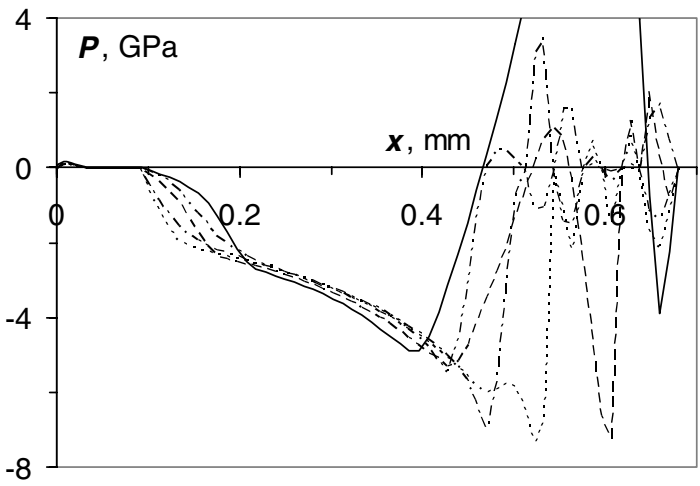

Fig. 12. The evolution of a tensile pulse in an iron sample under irradiation by an energy flux of $0.90 \mathrm{~kJ} / \mathrm{cm}^{2}: t=109.7 \mathrm{~ns}$ (solid line), $119.6 \mathrm{~ns}$ (dashed line), $130.2 \mathrm{~ns}$ (dotted line), $139.9 \mathrm{~ns}$ (dash-and-dot line) and 149.1 ns (dash-two-dots line).

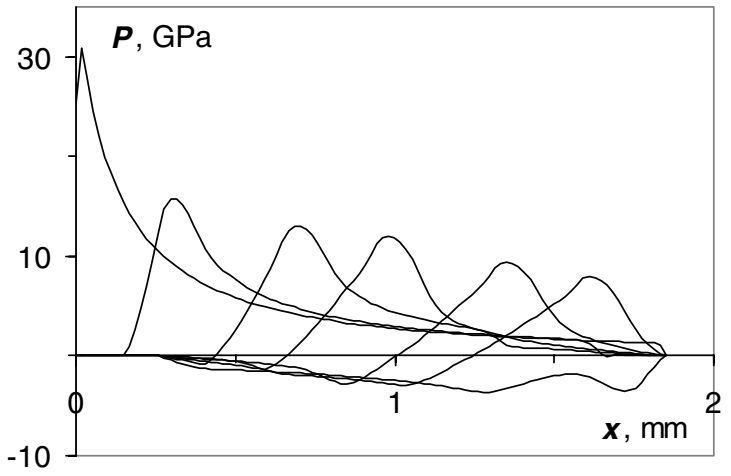

Fig. 13. The evolution of a compressive pulse in an AMg6 alloy sample under irradiation by an energy flux of $0.90 \mathrm{~kJ} / \mathrm{cm}^{2}: t=$ 2.0, 42.9, 100.6, 143.8, 201.4, 244.5 and $301.7 \mathrm{~ns}$.

to the formation of spall fracture may be considered only as the upper estimates of the real spall strength values.

\section{Discussion and conclusions}

The part of obtained experimental and calculated results on the damage of metals and alloys samples under fast heating by the intensive $\mathrm{X}$-ray pulse with the complete spectrum

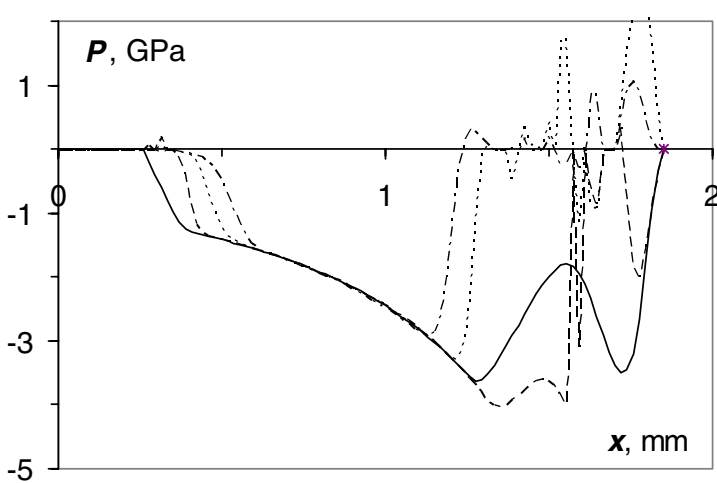

Fig. 14. The evolution of a tensile pulse in an AMg6 alloy sample under irradiation by an energy flux of $0.90 \mathrm{~kJ} / \mathrm{cm}^{2}: t=301.7 \mathrm{~ns}$ (solid line), $316.3 \mathrm{~ns}$ (dashed line), $330.9 \mathrm{~ns}$ (dotted line) and 344.9 ns (dash-and-dot line).

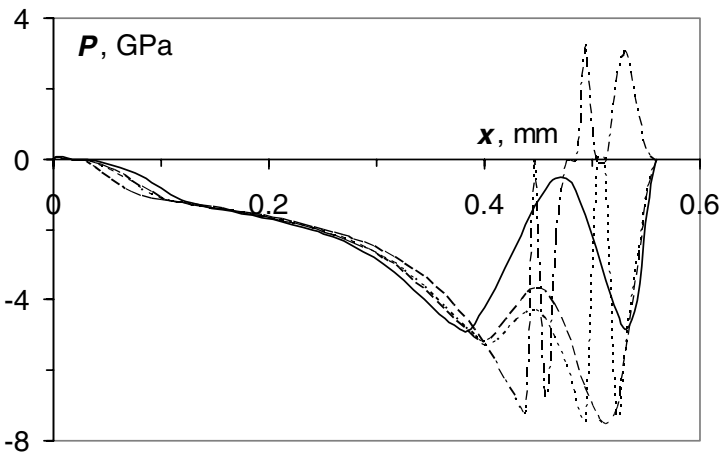

Fig. 15. The evolution of a tensile pulse in a copper sample under irradiation by an energy flux of $0.29 \mathrm{~kJ} / \mathrm{cm}^{2}: t=120.6 \mathrm{~ns}$ (solid line), $125.7 \mathrm{~ns}$ (dashed line), $126.9 \mathrm{~ns}$ (dotted line) and $133.1 \mathrm{~ns}$ (dash-and-dot line).

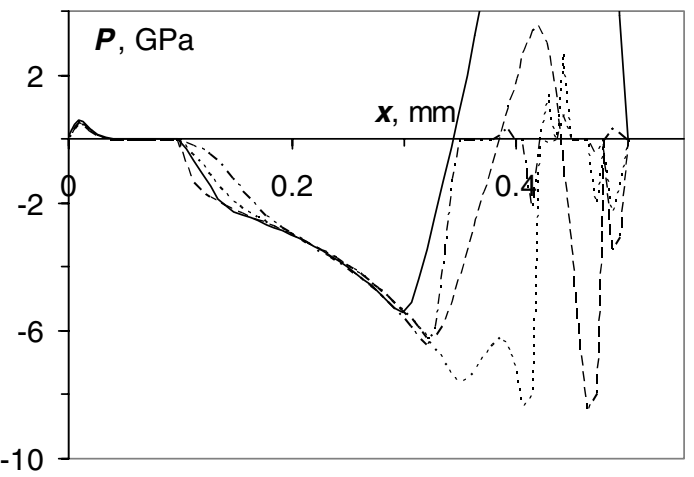

Fig. 16. The evolution of a tensile pulse in a molybdenum sample under irradiation by an energy flux of $0.90 \mathrm{~kJ} / \mathrm{cm}^{2}: t=75.6 \mathrm{~ns}$ (solid line), $81.5 \mathrm{~ns}$ (dashed line), $87.3 \mathrm{~ns}$ (dotted line) and $93.1 \mathrm{~ns}$ (dash-and-dot line).

have been presented in the paper. Some preliminary conclusions can be made on the basis of these results and their comparisons with the data on spall fracture of metals obtained in the conditions of fast heating by the X-ray pulse with the hard spectrum and the high-current electronic beam. As it was marked, the measurements of mechanical 
recoil momentums for various metals were conducted in the work. The generation of such a momentum was due to the gas-dynamic expansion of evaporated and melted materials. It can be noted that the agreement of experimental and calculated results was rather satisfactory in whole for the practical use. As for the values of ablation depth, they showed approximately linear relations on the values of energy flux practically for all examined materials.

All obtained experimental results on spall fracture of examined materials were compared with the mentioned data obtained in the other conditions of fast heating taking into account the positions of fracture zones, the temperatures of heating in these zones and the absence of spall damages under some heating conditions. The results obtained under X-ray irradiation for low-carbon steels, copper, titanium, tungsten, molybdenum, cadmium, lead and zinc [5], and the results obtained under electronic irradiation for copper, titanium, cadmium, lead and zinc [8], and for aluminum, 6061aluminum alloy, copper and titanium $[11,12]$ were used. In whole the consistent picture of influence of loading conditions, first of all loading time and temperature, on the fracture conditions under fast heating by penetrating radiation was noted for all examined materials.

As is known, temperature has influence not only on the strength properties of materials under shock wave loading but also on the character of spall fracture of many metals and alloys [24]. The comparison of results on the character of spall fracture of examined metals and alloys in the conditions of fast hating by X-ray radiation and of shock wave loading of preheated samples was carried out. A rather good agreement of such results was marked for all materials. From works used for comparison, it can be noted articles [25,26] in which results for iron and AMg6 aluminum alloy are given. For iron the agreement was also observed on the formation of recrystallization zones where the polymorphic transition took place under heating.

\section{References}

1. I.P. Borin, V.I. Lagutin, E.K. Bonyushkin et al., VANT. Pulsed Reactors and Simple Critical Assemblies (rus) 1, 40 (1985)

2. A.M. Molitvin, I.P. Borin, V.S.Bosamykin, Appl. Mech. Tech. Phys. (rus) 37(6), 116 (1996)

3. A.M. Molitvin, I.P. Borin, Metals (rus) 3, 93 (1998)

4. A.M. Molitvin, I.P. Borin, Metals (rus) 3, 97 (2001)

5. A.M. Molitvin, I.P. Borin, Proc. RFNC-VNIIEF 3, 314 (2002)

6. I.P. Borin, N.I. Zavada, A.M. Molitvin, A.Ya. Uchaev, Prod. Progr. Tech. Instr. Eng. (rus) 12, 34 (1985)

7. E.K. Bonyushkin, B.L. Glushak, N.I. Zavada et al., Appl. Mech. Tech. Phys. (rus) 37(6), 105 (1996)
8. E.K. Bonyushkin, N.I. Zavada, S.A. Novikov, A.Ya. Uchaev, Kinetics of Dynamic Fracture of Metals in the Conditions of Impulsive Volumetric Heating (RFNCVNIIEF, Sarov, 1998)

9. T. Stefansky, J.H. Shea, Dynamic Fracture Experiments Using High-energy Pulsed Electron Beams (Physics International Company, San Leandro, California, 1971)

10. R.R. Boade, O.L. Burchett, J. Appl. Phys. 47(8), 3412 (1976)

11. J.L. Perkin, E. Morris, D.W. Large, J. Phys. D Appl. Phys. 4(7), 974 (1971)

12. F.R.Tuler, Proc. XVII Sagamore Army Mater. Res. Conf. "Shock Waves and Mechanical Properties of Solids”, 395 (Syracuse University Press, Syracuse, New York, 1971)

13. V.K. Golubev, K.G. Rabinovich, A.K. Chernyshev, N.A.Yukina, Abstr. Int. Conf. "IV Zababakhin Scientific Talks”, 199 (RFNC-VNIITF, Snezhinsk, 1995)

14. V.K. Golubev, K.G. Rabinovich, A.K. Chernyshev, N.A.Yukina, Phys. Chem. Treat. Mater. (rus) 5, 9 (1996)

15. V.K. Golubev, K.G. Rabinovich, T.A. Kozlova, N.A. Yukina, Abstr. Int. Conf. "Shock Waves in Condensed Matter”, 53 (High Pressure SIC, Moscow, 1996)

16. V.K. Golubev, K.G. Rabinovich, A.K. Chernyshev, Met. Phys. Mod. Tech. (rus), 18(12), 26 (1996)

17. V.K. Golubev, K.G. Rabinovich, A.K. Chernyshev, N.A.Yukina, Appl. Mech. Tech. Phys. (rus) 38(1), 140 (1997)

18. V.K. Golubev, K.G.Rabinovich, A.K.Chernyshev, J. Tech. Phys. (rus) 68(2), 116 (1998)

19. V.K. Golubev, T.A. Kozlova, V.V. Khrustalev, Abstr. Int. Conf. "Shock Waves in Condensed Matter", 25 (St. Petersburg, 2000)

20. V.K. Golubev, Abstr. 8th Int. Workshop on Subsecond Thermophysics, 61 (JIHT, Moscow, 2007)

21. V.K. Golubev, K.G. Rabinovich, Proc. VII Sci. Conf. Volga Reg. RARAN Center "Modern Methods of Design and Adjustment of Rocket and Artillery Armaments" (RFNC-VNIIEF, Sarov, to be published)

22. Sapozhnikov A.T., Pershina A.V. VANT. Methods and Programs of Numerical Solution of Mathematical Physics Problems (rus) 2, 29 (1984)

23. Kuropatenko V.F., Kovalenko G.V., Kuznetsova V.I. et al., VANT. Mathematical Simulation of Physical Processes (rus) 2, 9 (1989)

24. V.K. Golubev, Proc. VII Sci. Conf. Volga Reg. RARAN Center "Modern Methods of Design and Adjustment of Rocket and Artillery Armaments" (RFNC-VNIIEF, Sarov, to be published)

25. V.K. Golubev, S.A. Novikov, Yu.S. Sobolev, N.A. Yukina, Problems of Strength (rus) 6, 28 (1985)

26. V.K. Golubev, A.I. Korshunov, S.A. Novikov et al., Appl. Mech. Tech. Phys. (rus) 29(2), 121 (1988) 